\title{
USE CASE POINT - ACTIVITY-BASED COSTING: METODE BARU UNTUK MENGESTIMASI BIAYA PENGEMBANGAN PERANGKAT LUNAK
}

\author{
Renny Sari Dewi, Apol Pribadi Subriadi, Sholiq \\ Jurusan Sistem Informasi, Fakultas Teknologi Informasi, Institut Teknologi Sepuluh Nopember \\ Kampus Keputih, Sukolio Surabaya 60111 \\ Telp: (031) 5999944, Fax: (031) 5964965 \\ E-mail: renny.rsd@gmail.com
}

\begin{abstract}
Resource forecast or estimation is an important part of a project planning, mainly for software development industry. Effort estimation (of work done) is one of frequently method used by project manager to estimate the resource allocation in every software development activity. Use Case Point $(U C P)$, as a method that is often used as a reference in calculation of effort estimation in software development, is still has not able to map the optimal resource usage based on activity. On the other hand, Activity-Based Costing (ABC) methods that focuses on activity-based financing resources able to cover the weaknesses of the UCP method. Thus the authors initiate that the combination of those two methods will create a breakthrough method based on UCP activity. Therefore, the authors then give that combination method as UCPabc integration model. The ouputs of this research is a concept model of UCPabc integration and also the calculation of software development cost estimation. Then the model is tested on software development project case, in this research we use example of a small-scale software development company projects. Those projects come from five government software development project which were done in the same year. As the result, the cost estimation using UPCabc is Rp 192.475.490 which has $2.16 \%$ greater deviation than the actual cost of the project itself (Rp 188.322.484). In addition, the authors also identify other outputs of the ABC method, such as: cost driver, cost pool, and cost object.
\end{abstract}

\section{Abstrak}

Estimasi atau perkiraan sumber daya merupakan bagian penting dari suatu perencanaan proyek, utamanya pada bisnis jasa pengembangan perangkat lunak. Estimasi effort (usaha yang dilakukan) adalah salah satu metode yang sering digunakan manajer proyek untuk memperkirakan alokasi pemakaian sumber daya disetiap aktivitas pengembangan proyek perangkat lunak. UCPabc (Use Case Point - Activity-Based Costing) merupakan variasi metode baru dari perluasan metode Use Case Point (UCP) yang selama ini telah dikenal dalam mengestimasi effort pengembangan perangkat lunak. Sedangkan dari sisi pembiayaannya akan digabungkan dengan metode sudah sering diimplementasikan yaitu Activity-Based Costing. Integrasi kedua metode ini diduga akan menjadi suatu terobosan baru dalam penyusunan komponen pembiayaan proyek pengembangan perangkat lunak. Dengan menggunakan metode UCPabc, estimasi biaya pengembangan perangkat lunak memiliki deviasi $2,16 \%$, lebih besar yaitu Rp 192.475.490. Angka deviasi tersebut diperoleh dari perbandingan estimasi UCPabc terhadap biaya aktual perusahaan yang sesungguhnya (Rp 188.322.484) pada lima proyek pengembangan perangkat lunak di lingkungan pemerintah daerah.

Kata kunci: estimasi, biaya, perangkat lunak, Use Case Point, ABC, Activity-Based Costing, UCPabc.

\section{PENDAHULUAN}

Perhitungan estimasi effort dan biaya proyek pengembangan perangkat lunak dapat menggunakan beberapa metode yang sudah ada, antara lain Source Line of Code (SLOC), Function Point Size Estimates (FP), Seer-Sem, Linear models, Multiplicative models, Constructive Cost Model (COCOMO), Putman" s model, dan Use Case Point (UCP). Keseluruhan metode estimasi effort tersebut memiliki kelebihan dan kekurangan masing-masing, sehingga metode yang akan digunakan merupakan yang paling sesuai dengan karakteristik proyek. Salah satu metode estimasi effort (usaha yang dilakukan) di awal langkah pengembangan perangkat lunak adalah metode Use Case Point (UCP) yang pertama kali diajukan oleh (Karner, 1993). Akhir-akhir ini, UCP semakin populer di dalam 
Dewi, dkk., Use Case Point - Activity-Based Costing: Metode Baru untuk Mengestimasi Biaya..

teknik estimasi effort pengembangan perangkat lunak. Hal tersebut tidak lepas dari studi yang dilakukan beberapa peneliti telah memberikan tingkat ketepatan estimasi yang cukup bagus, antara lain: (i) UCP lebih baik dari perkiraan para ahli, deviasi UCP $19 \%$ sedangkan deviasi para ahli adalah $20 \%$ (Anda, 2002); (ii) deviasi UCP memiliki deviasi 9\% pada estimasi 200 proyek pengembangan perangkat lunak (Carrol, 2005). Beberapa varian UCP juga dikembangkan oleh beberapa peneliti, antara lain: (i) UCPm adalah modifikasi UCP untuk pengembangan perangkat lunak dalam kondisi maintenance context (Diev, 2006); (ii) e-UCP yaitu modifikasi UCP dengan menambahkan naratif use case (Periyasamy \& Ghode, 2009); dan (iii) fuzzyUCP adalah modifikasi UCP dengan implementasikan teori fuzzy (Wang, Yang, Zhu, \& Chen, 2009) (Lee, Wen-Tin, \& Kuo, 2011).

Ada kelemahan mendasar (bersifat natural) dalam praktek estimasi effort dengan UCP atau variannya yaitu:

1. Hasil estimasi berupa nilai effort utuh - tidak didistribusikan per-aktivitas pengembangan perangkat lunak. Padahal, manajer proyek pengembangan perangkat lunak sangat memerlukan hasil estimasi terintegrasi ke dalam rencana pembagian effort ke masingmasing aktivitas pengembangan perangkat lunak.

2. Estimasi UCP tidak mengkaitkan dengan penggunaan sumber daya optimal berbasis pada aktivitas.

Di sisi lain, perkembangan Activity-Based Costing (ABC) sebagai teknik pembiayaan berbasis aktivitas sudah banyak diterapkan untuk pembiayaan implementasi Teknologi Informasi (TI), diantaranya: (i) ABC untuk evaluasi $e$ commerce (Roztocki, Activity-Based Costing for E-Commerce, 2001); (ii) $\mathrm{ABC}$ untuk implementasi TI/SI (Neumann, Gerlach, Moldauer, Finch, \& Olson, 2004) (Cleary, Gerdsen, \& O’Brien, 2006). Dari kajian literatur yang telah dilakukan, sejauh ini belum ditemukan suatu penelitian yang telah menginterasikan metode perhitungan $\mathrm{ABC}$ ke dalam metode perhitungan estimasi UCP. Gabungan kedua metode ini diduga akan menghasilkan perhitungan effort dan biaya pengembangan perangkat lunak yang lebih akurat dan transparan.

\subsection{Use Case Point}

Use Case Point merupakan suatu metode estimasi dalam pengembangan perangkat lunak (Karner, 1993). Metode ini memberikan sebuah estimasi yang mendekati estimasi sebenarnya yang dihasilkan dari pengalaman pembuatan atau pengembangan perangkat lunak. Hal tersebut dibuktikan oleh beberapa penelitian yang pernah dilakukan sebelumnya, dan menghasilkan pernyataan sebagai berikut:

a. UCP memiliki deviasi sebesar $6 \%$.

Persamaan UCP menghasilkan estimasi effort 367 man-days, sedangkan hasil actual effort 390 man-days sehingga terdapat deviasi sebesar 6 persen.

b. UCP memiliki deviasi sebesar $19 \%$, sementara estimasi para ahli memiliki ratarata deviasi sebesar 20\% (Anda, 2002).

c. UCP memiliki deviasi sebesar 9\% (Carrol, 2005).

Pada penelitian Carrol, disebutkan "setelah menerapkan proses yang cukup besar, ratusan proyek perangkat lunak (rata-rata 60 man-hours), ditunjukkan metrik yang membuktikan akurasi yang memperkirakan kurang dari $9 \%$ dari deviasi sebenarnya untuk biaya diperkirakan pada $95 \%$ dari proyek-proyek tersebut.

Tahapan perhitungan yang dirumuskan (Karner, 1993) adalah sebagai berikut:

1) Menghitung angka Unadjusted Use Case Point (UUCP)

Formulanya adalah:

$\mathrm{UUCP}=\mathrm{UUCW}+\mathrm{UAW}$

dimana untuk mendapatkan UUCP, harus dihitung terlebih dahulu Unadjusted Use Case Weight (UUCW) dan Unadjusted Actor Weight (UAW). Masing-masing use case memiliki tipe dan bobot yang. Tipe use case ditentukan berdasarkan jumlah transaksi per use case, dalam hal ini digunakan metode Roundtrip (Jacobson, Christorson, Jonsson, \& Overgaard, 1992). Perhatikan Tabel 1 .

Tabel 1. Tipe dan Pembobotan Use Case

\begin{tabular}{lcl}
\hline $\begin{array}{c}\text { Tipe Use } \\
\text { Case }\end{array}$ & Bobot & \multicolumn{1}{c}{ Keterangan } \\
\hline Sederhana & 5 & $\begin{array}{l}\text { Jumlah transaksi tidak } \\
\text { lebih dari 3 } \\
\text { Jumlah transaksi antara } \\
\text { Sedang hingga 7 } \\
\text { Jumlah transaksi lebih } \\
\text { dari 7 }\end{array}$ \\
\hline
\end{tabular}

UUCW $=($ Total Use Case Tipe Sederhana $\mathrm{x}$ 5) + (Total Use Case Tipe Sedang x 10) + (Total Use Case Tipe Sulit x 15).

2) Menghitung faktor kompleksitas teknis. Untuk mendapatkan nilai faktor kompleksitas teknis, tiap-tiap technical factor dikalikan dengan bobot. Lalu dijumlahkan secara keseluruhan dan dimasukkan pada formula berikut ini agar menghasilkan nilai Technical Complexity Factor (TCF).

$\mathrm{TCF}=0,6+(0,01 * \Sigma \mathrm{TF})$ 
3) Menghitung faktor kompleksitas lingkungan. Untuk mendapatkan nilai faktor kompleksitas lingkungan, setiap environmental factor dikalikan dengan bobot. Lalu dijumlahkan secara keseluruhan dan dimasukkan pada formula berikut ini agar menghasilkan nilai Environmental Complexity Factor (ECF).

$\mathrm{ECF}=1,4+(-0,03 * \Sigma \mathrm{EF})$

4) Menghitung Use Case Point

Apabila tiga langkah di atas selesai dihitung, maka selanjutnya adalah mendapatkan nilai UCP. Dari perolehan nilai UCP tersebut, maka actual effort dapat dihitung dengan mengalikan UCP dengan effort rate yang telah ditentukan. Formulanya adalah sebagai berikut:

$\mathrm{UCP}=\mathrm{UUCP} * \mathrm{TCF} * \mathrm{ECF}$

\subsection{Activity-Based Costing}

Activity-Based Costing (ABC) merupakan metode penentuan biaya produk yang dibebankan pada produk atau jasa sesuai konsumsi sumber daya yang disebabkan oleh aktivitas tertentu. Penyebab timbulnya biaya adalah penggunaan sumber daya yang melakukan beberapa aktivitas dalam menghasilkan suatu produk atau jasa. Pembebanan sumber daya tersebut mempengaruhi biaya dari aktivitas, yang kemudian dikenal dalam ABC adalah kausalitas aktivitas dengan pemicu biaya (cost driver) (Blocher, Chen, \& Lin, 2000).

Dari pengertian di atas, maka dapat disimpulkan bahwa $\mathrm{ABC}$ berorientasikan pada penyediaan informasi mengenai aktivitas dan biaya (Mulyadi, 2003). Dimana keterkaitan antara biaya dan aktivitas tersebut mampu mengindikasikan secara akurat dalam menentukan biaya produk/jasa. Oleh karena itu, ABC seringkali digunakan untuk mendapatkan harga pokok produk/jasa (AM, 2008). Penggunaan ABC dalam penelitian ini adalah bertujuan untuk mendistribusikan effort masing-masing aktivitas yang kemudian dapat dijadikan pembiayaan per aktivitasnya. Integrasi $\mathrm{ABC}$ pada UCP ini tentu memudahkan pihak manajemen yang berwenang dalam perusahaan, seperti manajer proyek, untuk mengetahui seberapa besar effort dan biaya dari masing-masing aktivitas dalam proyek pengembangan perangkat lunak.

\subsection{Penelitian Terdahulu}

Dalam dunia pengembangan perangkat lunak, seringkali acuan yang digunakan oleh para peneliti sebelumnya adalah bagaimana mengukur usaha (effort) pada proses pengembangan perangkat lunak. Beberapa penjelasan ataupun celah penelitian terdahulu mengenai UCP maupun $\mathrm{ABC}$ penulis cuplik sebagai berikut:
1) $\mathrm{ABC}$ diterapkan untuk luar perencanaan biaya sektor manufaktur. ABC sudah mulai banyak diterapkan pada sektor selain manufaktur, misalnya: layanan akademik (Ellis \& Newman, 2003), logistik dan pemasaran (Stapleton, Pati, Beach, \& Julmanichoti, 2004), dan ABC untuk biaya per siswa (Maelah, Amir, Ahmad, \& Auzair, 2011). Penelitian-penelitian ini sebagai landasan ide untuk penelitian ini, bahwa ABC dapat diterapkan di luar sektor manufaktur.

2) $\mathrm{ABC}$ untuk implementasi (atau evaluasi) Teknologi Informasi. ABC dapat memberikan beberapa manfaat untuk perusahaan ecommerce (Roztocki, Activity-Based Costing for E-Commerce, 2001). Selain $\mathrm{ABC}$ untuk membangun perangkat lunak untuk menghasilkan layanan TI (Neumann, Gerlach, Moldauer, Finch, \& Olson, 2004) (Cleary, Gerdsen, \& O’Brien, 2006).

3) Integrasi $\mathrm{ABC}$, value chain of activities, dan fuzzy logic. Sebuah framework dengan integrasi antara value chain of activities dengan ABC (Roztocki \& Weistroffer, 2004). Adapun Pengembangan dari penelitian terdahulu yang diterapkan di emerging economies. Temuan berupa sebuah framework dengan integrasi value chain of activities dengan ABC dan fuzzy logic untuk mengevaluasi investasi TI (Roztocki \& Weistroffer, 2005).

4) Effort setiap aktivitas dalam pengembangan perangkat lunak. Sebuah guideline untuk alokasi biaya dan effort untuk aktivitas pengembangan perangkat lunak medium dan besar menggunakan daftar kebutuhan yang ada. Terdiri dari 3 aktivitas utama, yaitu: (1) software development activities, (2) ongoing activities, dan (3) quality assurance and testing activities (Shaleh, 2011).

5) Use Case Point (UCP). Pertama kali mengajukan metode UCP untuk estimasi effort pengembangan perangkat lunak (Karner, 1993). UCP lebih baik dari estimasi para ahli, Tingkat deviasi UCP $19 \%$ dan para ahli 20\% (Anda, 2002). Hasil estimasi untuk 200 proyek didapatkan deviasi kurang dari $9 \%$ antara biaya aktual dan estimasi (Carrol, 2005). Nilai effort per orang-jam (man-hour) dalam pengembangan perangkat lunak yaitu 8,2 (Subriadi, Sholiq, \& Ningrum, Critical Review of The Effort Rate Value in Use Case Point Method For Estimating Software Development Effort, 2014).

6) Penelitian Terdahulu tentang Integrasi ABC dengan Fuzzy. Integrasi Fuzzy ABC memberikan model estimasi untuk digital library (Subriadi, Sholiq, \& Permadi, Cost Modelin $\mathrm{g}$ for Implementation of Digital Library System in Higher Education with Fuzzy 
Dewi, dkk., Use Case Point - Activity-Based Costing: Metode Baru untuk Mengestimasi Biaya..

Activity Based Costing, 2011) dan elearning (Sholiq, Subriadi, \& Algadri, 2011).

Ada dua kelemahan mendasar pada kedua penelitian tersebut (yang akan disempur-nakan pada penelitian ini):

a. Besarnya effort yang dilakukan masingmasing aktivitas pengembangan perang-kat lunak didapatkan dari justifikasi key person dalam organisasi berdasarkan expertise masing-masing key person. Sehingga nilai hasil estimasi sangat subyektif dan bias kepentingan dari key person.

b. Kedua penelitian tersebut mengambil fokus implementasi TI/SI secara umum. Jadi serupa dengan penelitian-penelitian terdahulu yaitu menghitung biaya untuk mendapatkan layanan TI/SI secara umum bukan fokus pada pengembangan perangkat lunak.

\section{METODOLOGI}

\subsection{Kerangka Berpikir}

Kerangka berpikir digunakan untuk memetakan pola pikir pada penelitian UCPabc ini. Berawal dari perhirtungan metode UCP, maka didapatkan nilai UCP per produk (perangkat lunak) dan persentase nilai relatifnya. Kedua, mengestimasi biaya berdasarkan metode ABC. Saat melakukan estimasi, digunakan acuan penelitian milik (Shaleh, 2011) untuk mengidentifikasi aktivitas dalam pengembangan perangkat lunak. Aktivitas tersebut selanjutnya dapat diketahui pemicu biaya dan kelompok biayanya, yang nantinya dapat dijadikan sebagai penyusun objek biaya. Ketiga, setelah persentase nilai relatif produk (luaran UCP) dan alokasi biaya per aktivitas ditentukan (luaran ABC), maka keduanya dapat digabungkan menjadi suatu perhitungan baru yaitu estimasi biaya berdasarkan integrasi UCPabc. Dan terakhir adalah pengujian atau validasi hasil perhitungan estimasi UCPabc dengan biaya yang sesungguhnya, sehingga dapat dilihat bahwa gap atau deviasi yang dihasilkan.

\subsection{Objek Penelitian}

Objek penelitian yang dijadikan penulis untuk melakukan pengujian hasil perhitungan estimasi biaya menggunakan metode UCPabc tersaji dalam Tabel 2.

Tabel 2. Gambaran Umum Objek Penelitian

\begin{tabular}{ll}
\hline Jenis perusahaan & $\begin{array}{l}\text { Jasa Konsultan } \\
\text { Teknologi Informasi } \\
\text { Pengembangan }\end{array}$ \\
Bidang keahlian & $\begin{array}{l}\text { perangkat lunak } \\
4 \text { orang }\end{array}$ \\
$\begin{array}{l}\text { Jumlah pegawai } \\
\text { tetap }\end{array}$ & 4 orang \\
$\begin{array}{l}\text { Jumlah pegawai } \\
\text { tidak tetap }\end{array}$ &
\end{tabular}

\begin{tabular}{ll}
\hline $\begin{array}{l}\text { Proyek yang } \\
\text { ditangani 2013 }\end{array}$ & 5 buah \\
$\begin{array}{l}\text { Lama pekerjaan } \\
\text { yang ditentukan }\end{array}$ & 12 bulan \\
$\begin{array}{l}\text { Pengalaman } \\
\text { perusahaan }\end{array}$ & 2 tahun (sejak 2011) \\
\hline
\end{tabular}

\section{HASIL DAN PEMBAHASAN}

\subsection{UCP untuk Mengestimasi Ukuran Perangkat Lunak}

Rumus perhitungan metode UCP sebelumnya telah dijelaskan pada poin pembahasan 2 . Sehingga pembahasan ini dititikberatkan pada penerapan formula tersebut untuk mendapatkan hasil yang akurat pada Tabel 4 .

Tabel 3. Informasi Umum Perangkat Lunak

\begin{tabular}{|c|c|c|}
\hline $\begin{array}{c}\text { No. } \\
\text { Proyek }\end{array}$ & $\begin{array}{c}\text { Nama Perangkat } \\
\text { Lunak }\end{array}$ & Teknologi \\
\hline 1 & Tanda Daftar Industri & $\begin{array}{c}\text { PHP, Oracle, } \\
\text { JQuery }\end{array}$ \\
\hline 2 & Izin Usaha Industri & $\begin{array}{l}\text { PHP, Oracle, } \\
\text { JQuery }\end{array}$ \\
\hline 3 & Persetujuan Prinsip & $\begin{array}{c}\text { PHP, Oracle, } \\
\text { JQuery }\end{array}$ \\
\hline 4 & $\begin{array}{l}\text { Tanda Daftar } \\
\text { Perusahaan }\end{array}$ & $\begin{array}{l}\text { PHP, Oracle, } \\
\text { JQuery }\end{array}$ \\
\hline 5 & $\begin{array}{l}\text { Sistem Informasi } \\
\text { Inventarisasi } \\
\text { Tanaman }\end{array}$ & $\begin{array}{c}\text { PHP, Oracle, } \\
\text { JQuery, Ajax, } \\
\text { HiChart }\end{array}$ \\
\hline
\end{tabular}

Tabel 4. Nilai UCP dan Persentase Nilai Relatif Produk

\begin{tabular}{crrr}
\hline $\begin{array}{c}\text { No. } \\
\text { Proyek }\end{array}$ & UUCP & $\begin{array}{c}\text { Use Case } \\
\text { Point (UCP) }\end{array}$ & $\begin{array}{c}\text { \% Nilai } \\
\text { Relatif } \\
\text { Produk }\end{array}$ \\
\hline 1 & 552 & 460,48 & $22,05 \%$ \\
2 & 567 & 472,99 & $22,65 \%$ \\
3 & 552 & 482,45 & $23,10 \%$ \\
4 & 499 & 501,56 & $24,01 \%$ \\
5 & 208 & 171,08 & $8,19 \%$ \\
Total & & $2.088,56$ & $100,00 \%$ \\
\hline
\end{tabular}

\subsection{ABC untuk Mengestimasi Biaya Perangkat Lunak}

Dalam mengestimasi biaya pengembangan perangkat lunak, maka ABC berperan sebagai penyusun komponen biaya sampai dengan level terkecil, yaitu aktivitas. Dari lima tahapan untuk mengimplementasikan metode $\mathrm{ABC}$, maka didapatkan beberapa luaran penting berikut ini:

Daftar Aktivitas

Ada 12 aktivitas inti yang dijelaskan oleh (Shaleh, 2011). Daftar aktivitas ini dapat dijadikan sebagai kelompok biaya (cost pool) yang sekaligus merupakan pemicu aktivitasnya.

Pembebanan biaya per aktivitas

Setiap aktivitas dalam pengembangan perangkat lunak, akan dibebankan biaya sesuai dengan 
persentase nilai relatif produk. Hal ini disebabkan oleh adanya biaya produksi yang digunakan bersama (joint product cost). Setelah dikalkulasi dan dikelompokkan biaya per aktivitas, maka didapatkan estimasi biayanya. Pada tahapan ini pula, pemicu biaya yang terdiri dari pemicu aktivitas dan pemicu sumber daya dapat diidentifikasi. Adapun pemicu aktivitas yang dimaksud adalah sejumlah subaktivitas penyusun dari aktivitas-aktivitas yang telah dijelaskan Tabel 5), ternyata mendekati angka estimasi biaya yang telah dikalkukasi. Sehingga apabila dibandingkan antara perhitungan estimasi biaya Tabel 5 menunjukkan perbandingan antara estimasi dan biaya aktual perusahaan beserta deviasi per aktivitasnya.

\section{SIMPULAN DAN SARAN}

Dari uraian di atas, maka beberapa hal yang dapat disimpulkan dari penelitian ini adalah sebagai berikut:

1. Perhitungan estimasi effort menggunakan metode UCP mampu menghasilkan persentase nilai relatif produk pada masing-masing proyek pengembangan perangkat lunak. Berikut rinciannya:

a) Tanda Daftar Industri: $22,05 \%$

b) Izin Usaha Industri: $22,65 \%$

c) Persetujuan Prinsip: $23,10 \%$

d) Tanda Daftar Perusahaan: 24,01\%

e) Sistem Informasi Inventarisasi Tanaman: $8,19 \%$

2. Total estimasi biaya menggunakan metode UCPabc adalah Rp 192.475.490, dengan rincian harga pokok produksi (HPP) masingmasing produknya sebagai berikut:
a) Tanda Daftar Industri: Rp 42.440.846
b) Izin Usaha Industri: Rp 43.595.698
c) Persetujuan Prinsip: Rp 44.461.838

sebelumnya (Shaleh, 2011). Untuk komponen pada pemicu biaya tenaga kerja, standar upah yang digunakan adalah panduan gaji di Indonesia (KellyServices, 2013).

\subsection{Estimasi UCPabc vs Biaya Aktual}

Berdasarkan perhitungan estimasi biaya menggunakan metode UCPabc, diperoleh nilai total Rp 192.475.490. Biaya aktual proyek (berdasarkan

UCPabc dengan realisasi perusahaan tahun 2013, maka terlihat rata-rata deviasi sebesar 2,16\%.

\section{d) Tanda Daftar Perusahaan: $\mathrm{Rp}$ 46.213.365}

e) Sistem Informasi Inventarisasi Tanaman: Rp 15.763.743

3. Dari perbandingan estimasi biaya menggunakan UCPabc dengan biaya aktual perusahaan, terdapat rata-rata deviasi $2,16 \%$ lebih besar. Namun sejatinya deviasi tersebut bergantung pada objek penelitian.

4. Manfaat yang dapat dirasakan manajer proyek adalah mengetahui aktivitas dan pemicu biaya secara lebih rinci yang menjadi penyusun biaya pengembangan perangkat lunak.

Saran untuk penelitian selanjutnya antara lain:

- Metode UCPabc masih perlu diuji pada perusahaan dengan sumber daya yang besar atau banyaknya jumlah proyek pengembangan perangkat lunak yang ditangani. Tentu hal ini berdampak pada biaya perusahaan.

- Aktivitas dalam pengembangan perangkat lunak juga memiliki andil dalam pembebanan biaya per aktivitasnya. Apabila aktivitas yang diadopsi lebih banyak atau lebih sedikit dari penelitian (Shaleh, 2011), maka tentu akan mempengaruhi effort dan biaya yang akan dikeluarkan perusahaan.

Tabel 5. Perbandingan Estimasi UCPabc vs Biaya Aktual

\begin{tabular}{|c|c|c|c|c|c|c|c|}
\hline \multirow{2}{*}{\multicolumn{2}{|c|}{$\begin{array}{r}\text { Aktivitas } \\
\text { Fase Pembanounan }\end{array}$}} & \multicolumn{2}{|c|}{ Estimasi UCPabc } & \multicolumn{2}{|c|}{ Biaya Aktual } & \multirow[t]{2}{*}{ Deviasi } & \multirow[t]{2}{*}{ Keterangan } \\
\hline & & & & & & & \\
\hline 1.1 & Penggalian kebutuhan & $\mathrm{Rp}$ & 3.094 .020 & $\mathrm{Rp}$ & 2.850 .000 & $7,89 \%$ & Lebih besar \\
\hline 1.2 & Analisis spesifikasi & $\mathrm{Rp}$ & 10.248 .131 & $\mathrm{Rp}$ & 8.840 .000 & $13,74 \%$ & Lebih besar \\
\hline 1.3 & Perancangan & $\mathrm{Rp}$ & 10.111 .856 & $\mathrm{Rp}$ & 8.060 .000 & $20,29 \%$ & Lebih besar \\
\hline 1.4 & Implementasi & $\mathrm{Rp}$ & 38.664 .760 & $\mathrm{Rp}$ & 33.205 .000 & $14,12 \%$ & Lebih besar \\
\hline 1.5 & Pengujian \& integrasi & $\mathrm{Rp}$ & 7.695 .139 & $\mathrm{Rp}$ & 10.190 .000 & $-32,42 \%$ & Lebih kecil \\
\hline 1.6 & $\begin{array}{l}\text { Penerimaan \& } \\
\text { penyebaran }\end{array}$ & $\mathrm{Rp}$ & 6.575 .861 & $\mathrm{Rp}$ & 7.410 .000 & $-12,68 \%$ & Lebih kecil \\
\hline \multicolumn{8}{|c|}{ Fase Yang Sedang Berlangsung } \\
\hline 2.1 & Manaj. Proyek & $\mathrm{Rp}$ & 95.496 .487 & $\mathrm{Rp}$ & 95.456 .784 & $0,04 \%$ & Lebih besar \\
\hline 2.2 & Manaj. konfigurasi & $\mathrm{Rp}$ & 2.875 .278 & $\mathrm{Rp}$ & 2.270 .000 & $21,05 \%$ & Lebih besar \\
\hline 2.3 & Penjaminan mutu & $\mathrm{Rp}$ & 3.032 .727 & $\mathrm{Rp}$ & 3.408 .400 & $-12,39 \%$ & Lebih kecil \\
\hline 2.4 & Dokumentasi & $\mathrm{Rp}$ & 8.514 .040 & $\mathrm{Rp}$ & 7.170 .000 & $15,79 \%$ & Lebih besar \\
\hline 2.5 & Pelatihan \& dukungan & $\mathrm{Rp}$ & 3.173 .692 & $\mathrm{Rp}$ & 4.712 .000 & $-48,47 \%$ & Lebih kecil \\
\hline 2.6 & Evaluasi \& pengujian & $\mathrm{Rp}$ & 2.993 .497 & $\mathrm{Rp}$ & 4.750 .300 & $-58,69 \%$ & Lebih kecil \\
\hline $\mathbf{R p}$ & 192.475.490 Rp & 188.322.484 & $2,16 \%$ & \multicolumn{2}{|c|}{ Lebih besar } & & \\
\hline
\end{tabular}


Dewi, dkk., Use Case Point - Activity-Based Costing: Metode Baru untuk Mengestimasi Biaya..

\section{DAFTAR RUJUKAN}

AM, M., 2008. Analisis Biaya dengan Metode Activity Based Costing Kepaniteraan Klinik Mahasiswa Fakultas Kedokteran Unissula di Rumah Sakit Pendidikan (Studi Kasus di Rumah Sakit Islam Sultan Agung). Semarang: Universitas Diponegoro.

Anda, B., 2002. Comparing effort estimates based on use cases with expert estimates. Empirical Assessment in Software Engineering (EASE) (hal. 13). Keele UK: Proceeding of Empirical Assessment in Software Engineering (EASE).

Blocher, E., Chen, K., \& Lin, T., 2000. Manajemen Biaya: dengan Tekanan Stratejik. Jakarta: Penerbit Salemba Empat.

Carrol, E. R. 2005. Estimating Software Based on Use Case Points. Object Oriented Programming Systems Languages and Applications (OOPSLA) Conference (hal. 257-265). San Diego: ACM.

Cleary, J., Gerdsen, T., \& O’Brien, L. 2006. The Activity Based Costing of Library and Information Technology Services in Higher Education.

Diev, S. 2006. Software Estimation in the Maintenance Context. Software Engineering Notes, ACM, 31(2), 1-8.

Ellis, J., \& Newman. 2003. Activity-Based Costing in User Services of an Academic Library. Library Trends, 51(Winter 2003), 333-348.

Jacobson, I., Christorson, M., Jonsson, P., \& Overgaard, G. 1992. Object-Oriented Software Engineering. A Use Case Driven Approach (Revised Printing ed.). AddisonWesley.

Karner, G. 1993. Resource Estimation for Objectory Projects. Objective Systems $S F A B$.

KellyServices. 2013. Indonesia Salary Guide | Kelly Services. Dipetik June 20, 2014, dari http://kellyservices.co.id/ID/ResourceCentre/Salary-Guide/

Lee, J., Wen-Tin, L., \& Kuo, J.-Y. 2011. Fuzzy Logic as a Basic for Use Case Point Estimation. International Conference on Fuzzy Systems (hal. 2702-2707). Taipe Taiwan: IEEE.

Maelah, R., Amir, A. M., Ahmad, A., \& Auzair, S. M. 2011. Cost per Student Using ABC Approach: A Case Study. International Conference on Economics and Business Information. 9. Bangkok: IACSIT Press,.

Mulyadi. 2003. Activity Based Cost System Sistem Informasi Biaya untuk. Yogyakarta: UPPAMP YKPN.
Neumann, R. B., Gerlach, H. J., Moldauer, E., Finch, M., \& Olson, C. 2004. Cost Management Using $\mathrm{ABC}$ for IT Activities and Services. Management Accounting Quarterly, 6(1), 29-40.

Periyasamy, K., \& Ghode, A. 2009. Cost Estimation using extended Use Case Point (e-UCP) Model. IEEE.

Roztocki, N. 2001. Activity-Based Costing for ECommerce. Engineering research 2001 Conference. Proceedings from the Industrial Engineering.

Roztocki, N., \& Weistroffer, H. R. 2004. Using Activity-Based Costing for Evaluating Information Technology Related Investments in Emerging Economies: A Framework. Proceedings of the Tenth Americas Conference on Information Systems, (hal. 642-645). New York.

Roztocki, N., \& Weistroffer, H. R. 2005. Evaluating Information Technology Investments: A Fuzzy Activity-Based Costing Approach. Journal of Information Science and Technology SSRN, 2(4), 30-43.

Shaleh, K. 2011. Effort and Cost Allocation in Medium to Large Software Development Project. International Journal of Computer, 5(1), 74-79.

Sholiq, Subriadi, A. P., \& Algadri, A. N. 2011. Cost Modeling for E-learning Implementation in Higher Education with Fuzzy Activity Based Costing. Gematika, 11(1), 11-18.

Stapleton, D., Pati, S., Beach, E., \& Julmanichoti, P. 2004. Activity-based costing for logistics and marketing. Business Process Management Journal - Emerald, 10(5), 584-597.

Subriadi, A. P., Sholiq, \& Ningrum, P. A. 2014. Critical Review of The Effort Rate Value in Use Case Point Method For Estimating Software Development Effort. Journal of Theoretical and Applied Information Technology, 59(3), 735-744.

Subriadi, A. P., Sholiq, \& Permadi, G. 2011. Cost Modeling for Implementation of Digital Library System in Higher Education with Fuzzy Activity Based Costing. Information Systems International Conference (ISICO) 2011. Surabaya.

Wang, F., Yang, X., Zhu, X., \& Chen, L. 2009. Extended Use Case Points Method For Software Cost Estimation. Computational Intelligence and Software Engineering (hal. 1-5). Wuhan: IEEE. 